\title{
ELECTROENCEPHALOGRAPHY IN CONGENITAL MALFORMATIONS OF THE CENTRAL NERVOUS SYSTEM
}

\author{
PATRICIA CAMPOS*, GUILLERMO CRUZ **, RODOLFO LIZARRAGA ***, ERNESTO BANCALARI****,

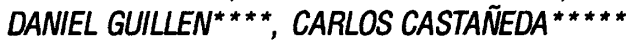

\begin{abstract}
SUMMARY - We studied clinical and EEG features of 36 cases with congenital malformations of the CNS. Patients were followed at the outpatient clinic of Hospital Cayetano Heredia and of Hogar Clinica San Juan de Dios in Lima-Peru, from January 1984 to June 1992. Eighty percent of the patients had convulsive syndromes and mental retardation. The most frequent malformation was agenesis of corpus callosum, and it was not possible to find a "typical" EEG pattern. The second were porencephalic cysts, with a good clinical-EEG correlation. There were two typical cases of schizencephaly, one of hemimegalencephaly with good prognosis, and one of holoprosencephaly. The results are compared to those obtained for a series we previously reported. Data discussed take into account reports on the subject registered in the literature. It is concluded that EEG is an useful method to evaluate possible CNS malformations in developing countries.
\end{abstract}

KEY WORDS: central nervous system, congenital malformations, corpus callosum agnesis, porencephaly, hemimegalencephaly, hydrocephaly, EEG.

\section{Electroencefalografia en las malformaciones congénitas del sistema nervioso central}

RESUMEN - Estudiamos aspectos clínicos e del EEG de 36 casos de malformaciones congénitas del sistema nervioso central. Los pacientes fueron seguidos en los consultorios externos del Hospital Cayetano Heredia y del Hogar Clínica San Juan de Dios en Lima-Peru, desde enero 1984 hasta junio 1992. Ochenta por ciento de los pacientes presentaron sindrome convulsivo y retardo mental. La anormalidad mas frecuente correspondio a agenesia de cuerpo calloso y no fue posible identificar un patron EEG "típico". El segundo lugar correspondio a quistes porencefálicos, con buena correlacion clínico-EEG. Ademas, hubieron dos casos clinicamente típicos de esquizencefalia, una hemimegalencefalia con buen prognóstico y un caso de holoprosencefalia. Se comparan los resultados con aquellos de casos previamente revisados. Se discuten los dados frente a la literatura acerca de los patrones EEG mas frecuentemente relatados. Se concluye en la utilidad del EEG en paises en desarrollo para hacer posible un alto grado de sospecha de una malformacion del SNC aun en ausencia de CAT-scan.

PALABRAS-CLAVE: sistema nervioso central, malformaciones, agenesia de cuerpo calloso, porencefalia, hemimegalencefalia, holoprosencefalia, EEG.

The congenital anormalies of the central nervous system (CNS) represent a frequent cause of fetal and perinatal death. Together with congenital errors of the metabolism, chromosomopathies and vascular abnormalities, they play a major role in the pathology of the cerebral lesions responsible for mental retardation and/or cerebral paralysis, associated or not with convulsive syndromes ${ }^{17,30}$.

*Neuropediatrist, Hospital Cayetano Heredia, Universidad Peruana Cayetano Heredia; **Neurologist and Electroencephalographist, Instituto Peruano de Seguridad Social; ***Neurologist and Electroencephalographist, Hospital de la Sanidad de las Fuerzas Policiales; ****Neurologist, Hospital Cayetano Heredia; *****Neurologist, Instituto Nacional de Enfermedades Neurológicas. Aceite: 10-junho-1994.

Dra. Patricia Campos - Dos de Mayo 649 - Lima 27 - Perú. 
The availability of new methods of neuroimage have made possible a better knowledge of each one of them, which on occasions were only anatomical findings.

The goal of this paper is to review the clinical and EEG features of some CNS congenital malformations and show our experience about this correlation, and also comparing it with other Latin American reported cases 5 . We also call attention about specific EEG patterns we can use to suspect these congenital malformations.

\section{MATERIAL AND METHODS}

We present 36 patients selected from a total of 52, studied with at least one EEG recording and who were consecutively observed within a period of more than 8 years, since January 1984 to July 1992 . The patients were examined in the neuropediatric outpatient clinic of Hospital General Cayetano Heredia and of Hogar Clinica San Juan de Dios (HCSJD), and the patients were carried from two sources: the general archives of patients; and EEG files of the HCSJD (operating since 1989), which up to date totalize 2100 records.

The patients were selected by CAT-scan image, preferring the most import malformations and excluding the symmetric and asymmetric cortico-subcortical atrophies in spite of knowing they have not another origin, and some ventricular abnormalities of unknown cause. We excluded patients without follow-up for more than 6 months and patients without EEG.

The EEG records were obtained with Grass, Nihon-Kohden and Alvar equipment with 8 channels, with a speed of $30 \mathrm{~mm} / \mathrm{sec}$ and C.T. O.3. The electrodes placing was performed in accordance with the international system 10-20.

The previous cases, presented in 1983, comprised 115 cases collected between 1972 and 1982 (out of a 228 patients series which also included cases of hydranencephaly and cranial abnormalities)'. They were collected in the EEG Section of the Neurologic Clinics of the Hospital das Clinicas of the University of São Paulo School of Medicine (Brasil), which had 105000 EEG records. The equipment used then were Kaiser and Berger with 8 channels, and the records were practiced in accordance with the norms previously mentioned.

\section{RESULTS}

Of the 36 patients, $20(58 \%)$ were male and $16(42 \%)$ were female, with ages between 44 days and 13 years 8 months at the time of the examination; $39(80 \%)$ complained of convulsive syndromes of different classes and mental retardation (or development retardation) with or without neurological deficit; 6 (18\%) complained only of psychomotor development retardation; and 1 (2\%) of cephalic perimeter increase (Table 1 ).

We had 17 patients with corpus callosum agenesis (Table 2), 16 of them associated with some malformations: cortical/subcortical atrophy in 4 , global in 6 , single ventricules in 5 , third ventricle cyst in 3 (one of them with meningoencephalocele). We had one case of Aicardi syndrome. Clinically, the most frequent finding was mental retardation and convulsive syndrome in 13 of 17 patients (76\%). EEG showed 5 hypsarrhythmias (one alternate, corresponding to Aicardi syndrome), 5 with wave-and-spike less than $2.5 \mathrm{~Hz}, 4$ normal, 2 multifocal, 1 with generalized electricus status and 1 slow diffuse.

Table 1. Congenital malformations of the CNS.

\begin{tabular}{|c|c|c|c|c|}
\hline & 1983 & series & Present & series \\
\hline & $\mathrm{n}^{\circ}$ & $\%$ & $n^{0}$ & $\%$ \\
\hline Agenesis corpus callosum & 5 & 6.2 & 17 & 47 \\
\hline Arrhinencephaly-Holoprosencephaly & 0 & 0 & 1 & 3.8 \\
\hline Porencephaly & 9 & 7.8 & 9 & 25 \\
\hline Hemimegalencephaly & 0 & 0 & 2 & 5.6 \\
\hline Schizencephaly & 0 & 0 & 2 & 5.6 \\
\hline Hydrocephaly & 101 & 86 & 5 & 13 \\
\hline
\end{tabular}


Table 2. Agenesis of the corpus callosum and Aicardi syndrome.

Patients

EEG pattern

1983 series Present series

Normal

Focal paroxysmic activity

Electrografic crisis

Generalized paroxysmic activity with or without background

activity alteration

Mixed patterns with suppression salves

Hypsarrhythmia

Multifocal

Diffuse slowness

Electric status

$\begin{array}{ll}1 & 4 \\ 1 & - \\ 1 & - \\ 1 & 1 \\ 1 & 4 \\ - & 4 \\ - & 2 \\ - & 1 \\ - & 1\end{array}$

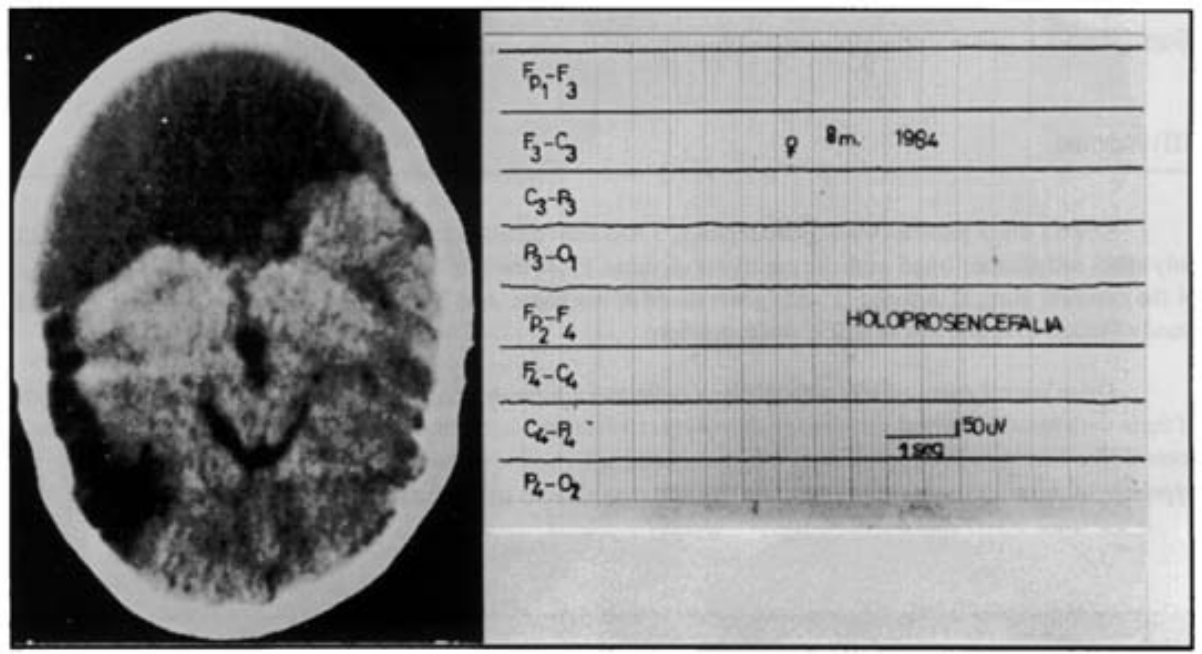

Fig 1. Holoprosencephaly: TC and EEG (almost complete electric silence).

There was only one patient with holoprosencephaly, a girl with infantile spasms and severe psychomotor retardation whose EEG showed an almost complete cerebral electric silence, and who died before two years old (Fig 1).

We had 9 patients with porencephalic cysts (Table 3 ). Clinically 8 (88\%) showed development retardation and convulsive crisis, being partial in 5 and generalized in 3 (one with infantile spasms). Six of them (66\%) had also motor deficit. Four EEG corresponded to focal irritative activity, 2 paroxysmic generalized activity, 1 with hemispheric slowness and 1 normal.

We had 2 patients with hemimegalencephaly, female and male of 8 and 20 months respectively. The first with development retardation, mixed infantile spasms and motor deficit, whose EEG showed hemihypsanthythmia; presently she is $\mathbf{5}$ years old and is asymptomatic, without crisis and with good intellectual development (Fig 2). The second patient had generalized paroxysmic activity on the EEG and mixed convulsive syndrome. 
Table 3. Porencephaly.

\section{Patients}

EEG pattem

1983 series Present series

I) Generalized

Paroxysmal activity

Diffuse depression

Hypsarrhythmia

$\begin{array}{ll}1 & 2 \\ 1 & 0 \\ 0 & 1\end{array}$

II) Focal

Paroxysmal activity

Voltage asymmetry

Frequence asymmetry

Hemispheric slowness

$\begin{array}{ll}1 & 4 \\ 1 & 0 \\ 1 & 0 \\ 0 & 1\end{array}$

Background + paroxysmal abnormality

Among the 5 patients with hydrocephaly, 3 had convulsive crisis and psychomotor retardations, 1 had only crisis and another 1 had cephalic perimeter increase. From the EEG point of view: 2 with diffuse depression of the cerebral cortical activity, 2 with generalized spike-wave, and 1 normal (curiously this had associated Dandy Walker cyst and 3rd ventricle malformation).

There were 2 cases of schizencephaly, a male and a woman of 6 months and 12 years respectively, both of them with spastic cerebral paralysis (quadriplegia), severe mental retardation and convulsive disorder without control (the first with West syndrome, and the second with Lennox-Gastaut syndrome). The EEG was typical, hypsarrhythmia with suppression salves in the first, and diffuse paroxysmic activity in the second.

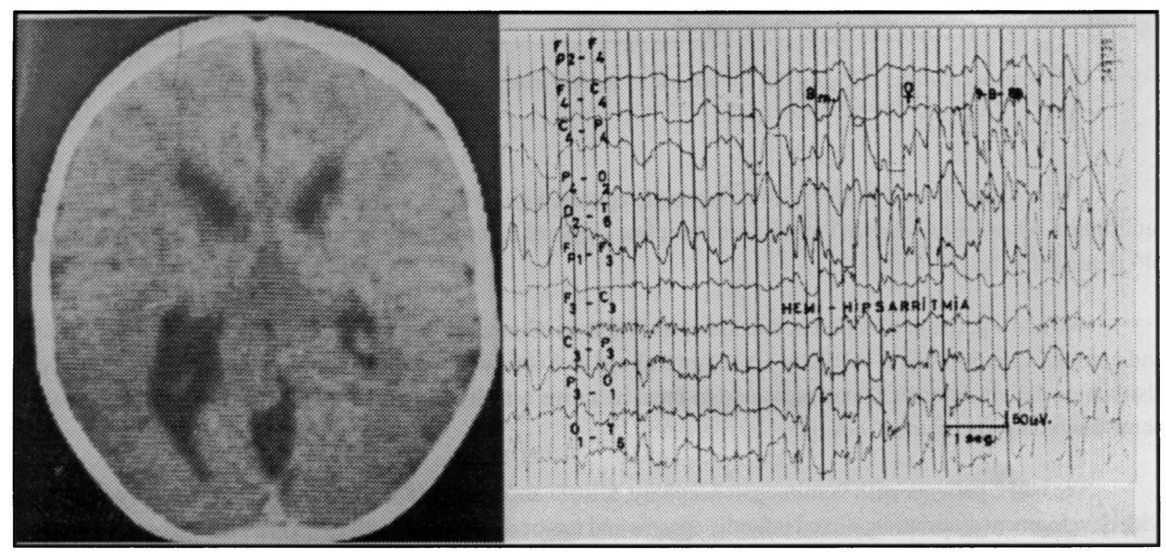

Fig 2. Hemimegalencephaly: TC and EEG (hemihypsarrythmia). 
In relation to the previous series of cases ${ }^{5}$, from 5 cases of corpus callosum agenesis, 3 had psychomotor retardation. The EEG pattern was normal in 1 and showed hypsarrhythmia in the other. In 3 we could not obtain the record. From the 9 cases of porencephalic cyst, all had evident motor deficit, convulsive crisis and psychomotor retardation. The EEG showed background activity alteration in 4 (voltage asymmetry), paroxysmic activity only in 2 ( 1 diffuse, 1 localized), and both components in 3 . In the group of hydrocephalies, $65 \%$ were normal, $23 \%$ had altered background and paroxysmal activity and $12 \%$ only with paoxysmal activity.

\section{COMMENTS}

The incidence of congenital cerebral malformations is variable in accordance with different reports ${ }^{2}$, specially at present due to technological and genetical advances. Discovering of alterations in cellular migration and the so called "cortical dysplasia" are outstanding, in such a way that some today called malformations are know to be cellular migration alterations (v.g. schizencephaly). However, in the $80 \mathrm{~s}$ it was a general thinking that most frequent malformations at birth were hydrocephaly, microcephaly and craniosynostosis. We describe below the malformations and their EEG patterns.

AGENESIS OF THE CORPUS CALLOSUM, partial or total, is an entity of which it is not known if clinical and EEG alterations are due to agenesis itself or to other associated malformations like microcephaly, porencephaly, cellular heterotopies, congenital hydrocephaly due to Monro foramen obstruction ${ }^{4,16,19}$. Their association with unique ventricle has also been described, and in complete agenesis the malformation is severe as in cases of arrhinencephaly and cyclopias with or without presence of inter-hemispheric colloidal cysts. In 1964 Goldensohn et al. ${ }^{13}$ described the first case in whom EEG was traced, showing inter-hemispheric asynchronism particulary in the occipital region and slow diffuse waves of 6-7 Hz with more than $150 \mathrm{uV}$ of amplitude. Toglia and Lapayowker ${ }^{29}$ in relation to 8 cases corroborated this pattern. Green and Russel ${ }^{14}$ described a case of partial agenesis of the corpus callosum with alpha activity hemispheric independence and asynchronic return of this activity after blocking. Fariello et al. ${ }^{9}$ described multifocal spasms with suppression burts and asynchronism in Aicardi syndrome ${ }^{1}$, particularly in early stages.

Among the 5 cases presented in $1983^{5}$, there was only one case of this group without special features and normal tracing. Among the 17 cases of present series, only the case of Aicardi syndrome had typical EEG. The remaining cases presented non characteristic patterns, a fact that call attention. The inter-hemispheric asynchrony finding in a patient with psychomotor retardation and infantile spasms suggest the diagnosis of that malformation.

ARRHINENCEPHALY is defined as the minimum expression of allobar holoprosencephaly without inter-hemispheric fissure ${ }^{26}$. In accordance with the literature it can show the following EEG patterns: isoelectric activity ${ }^{28}$, depression areas or periodic discharges of paroxysmic nature and subclinical critical activity ${ }^{8}$. Our case of holoprosencephaly showed the expected isoelectric activity pattern.

PORENCEPHALY is defined as the presence of one or more cavities communicating with the ventricular system, the subarachnoid space, or both ${ }^{15}$. It deserves commentaries because it is one of the most know congenital malformations and it has the highest frequency of associations with microcephaly, agenesis of corpus callosum, encephalocele, cerebellar hypoplasia, and thalamus fusion. As early as 1947, Murphy and Garvin ${ }^{22}$ referred normal patterns, specially if the cysts were small: afterwards, various authors agree in considering two EEG recordings as the more characteristics: diffuse or hemispheric slow rhythms, and depression of the focal electrical activity associated or not with slow or paroxysmic activity in this case, the depression is related to the presence of fluid or non functional cortex, whereas the paroxysmic activity is associated with gliosis or other degenerative changes. Carmon et al..$^{6}$ observed that development of EEG abnormalities has close relationship with clinical development, and concluded that the EEG findings were dynamic and preceded X-ray changes. Freeman ${ }^{11}$ found the abnormality in up to $85 \%$ of cases with slow activity and low voltage in the area of the cyst. 
In the first series ${ }^{5}$, in relation to the 9 cases EEG abnormalities found were varied without prevalence of any special pattern; in the case that had the largest cyst, paroxystic alterations were more patent than changes in background activity. In our present cases, the EEG alterations were more defined, both for generalized as for focal activity, conforming the classical triad of mental retardation, crisis, and motor deficit. We also had one hypsarrhythmia, and one normal EEG in a child without convulsive crisis.

HEMIMEGALENCEPHALY is a rare congenital malformations that consists of hyperthophy of one cerebral hemisphere with ventricular dilation on the same side. It is frequently associated with other cerebral malformations and cortical dysgenesis. Often, its prognosis is severe, resulting in a precocious death. The EEG studies are scarce ${ }^{7,27}$ from the first one described by Tjiam in $1978^{28}$ until the one described by Paladin et al. ${ }^{24}$ in 1989, and the one of Fusco et al. ${ }^{12}$ in 1992 . Thus, hemihypsarrhythmias, triphasic wave complexes, asymmetric burst-suppression patterns, alpha-like activity and very fast beta rhythms with diffuse spike-wave complexes were described. Paladin et al. established prognosis in relation to these patterns, showing better prognosis for sequelae and crisis control in the alpha-like activity type.

In our present series we had only one case with infantile spasms and hemihysarrhythmia but with excellent prognosis. At present she has normal intelligence and is completely free of crisis for almost 5 years. The other patient has a Lennox-Gastaut syndrome partially controlled.

HYDROCEPHALY deserves commentaries. According to Fois and Gibbs ${ }^{10}$ the most frequent abnormality found is the asynchronism of sleeping spindles and vertex waves. Pampiglione and Lawrence ${ }^{25}$ concluded that EEG alterations have a direct relationship with type, timing and distribution of lesions responsible for the development of hydrocephaly. Bogacz and Rebollo ${ }^{3}$ considered three groups of abnormalities, in relation to 17 cases: delta polymorphic with temporary predominance which replaces the sleeping spindles, paroxysmic activit, and generalized abnormality.

Among the 101 patients from $1983^{5}, 65 \%$ showed normal patterns, $13 \%$ paroxysmic activity (mainly focal or multifocal rather than diffuse), $12 \%$ background activity alteration (mainly depression or diffuse disorganization) and $10 \%$ showed a combination of paroxysmic activity and background activity alteration. Among our present cases, 2 corresponded to a background electrical activity depression, 2 had generalized spike-wave activity as described by Bogacz and Rebollo, and we did not find any asynchronism pattern during sleep.

SCHIZENCEPHALY was introduced as it in 1946 by Yakovlev and Wadsworth ${ }^{31,32}$ and until then there were only post-mortem studies. Presently it represents the most common cerebral malformation attributed to cellular migration defects, and it consists on uni or bilateral cerebral fissures ${ }^{21,23}$ associated or not hydrocephaly. Clinically, it shows syndromes with very bad prognosis, with severe mental retardation and intractable epilepsy. Unilateral forms can be associated with better life quality ${ }^{20}$. EEG findings are scarcely defined on the literature. Diffuse slowness and associated spike temporal focus have been described ${ }^{12}$. Of our two cases one corresponded to a typical West syndrome with hypsarrhthmia, and the other to a Lennox-Gastaut mixed type epilepsy with diffuse paroxysm activity. Severe mental retardation and intractable epilepsy occurred in these two patients.

In conclusion we can say that:

1. It is important to remember that the absence of one portion of the brain do not necessary cause an EEG abnormality, whereas structural distorctions, cortical dysgenesis and gliotic zones can be electrically more actives.

2. Althrough literature data show typical EEG patterns for various congenital malformations, in our present series a good EEG correlation was found only in cases of porencephaly and hemimegalencephaly. In relation to the other cases, the Aicardi syndrome had a typical EEG, none 
of the hydrocephalies had asynchronism of sleep spindles, and the two schizencephalies had typical West and Lennox-Gastaut EEG patterns.

3. In developing countries it is important to remember that these "frequent and more or less characteristics" EEG patterns can make highly suspected a defined congenital malformation even without CAT-scan (v.g. to discriminate between hydrocephaly and hydranencephaly in a patient with increase in the cephalic perimeter).

\section{REFERENCES}

1. Aicardi J, Chevrie JJ, Rousselie F. Le syndrome spasmes en flexion agenesie calleuse, anomalies chorioretiniennes. Arch Franc Pediatr 1960, 26: 1103-1120.

2. Baraitser M. The genetics of neurological disorders. Ed 2. London: Oxford Med Publ, 1990.

3. Bogacz J, Rebollo MA. Electroencephalographic abnormalities in non tumor hydrocephalus. EEG Clin Neurophysiol 1962, 14: 123-125.

4. Brun A, Probst F. The influence of associated cerebral lesions on the morphology of the acallosal brain: a pathological and encephalographic study. Neuroradiology 1973, 6: 121-131.

5. Campos P, Hannuch S, Grossmann R, Longo PH, Ferreira de Andrade MJ. EEG en las malformaciones congenitas del sistema nervioso central. Relato oficial. VIII Congreso Peruano de EEG y Neurofisiologia Clinica, Lima-Peru, Octubre 1983.

6. Carmon A, Lavy S, Schwartz A. The dynamics of electroenphalographic abnormalities in porencephalia. Neurology 1964, 14: 757-763.

7. Damsbka M, Wisniewski K, Sher J. An autopsy case of hemimegalencephaly Brain Dev 1984, 6: 60-64.

8. De Myer W, White PT. EEG in holoprosencephaly (archinencephaly). Arch Neurol 1964, 11: 507-520.

9. Fariello R, Chun R, Doro JM, Buncie J, Prichard JS. EEG recognition of Aicardi's syndrome. Arch Neurol 1977, 34: 563-566.

10. Fois A, Gibbs EL, Gibbs FA. Bilaterally independent sleep patterns in hydrocephalus. Arch Neurol Psychiatry 1958, 79: 264-268.

11. Freeman JM, Gold AP. Porencephaly simulating subdural hematoma in childhood: a clinical syndrome secondary to arterial occlusion. Am J Dis Child 1964, 107: 327-336.

12. Fusco L, Ferracuti S, Fariello G, Manfredi M, Vigevano F. Hemimegalencephaly and normal intellectual development. J Neurol Neurosurg Psychiatry 1992, 55: 720-722.

13. Goldenshoh LN, Clardy ER, Levine K. Agenesis of the corpus callosum. J Nerv Ment Dis 1941, 93: 5567-5580.

14. Green JB, Russell AJ. Electroencephalographic asymmetric with midline cyst and deficient corpus callosum: case report. Neurology 1966, 16: 541-545.

15. Gross H, Simányi M. Porencephaly. In Vinken PJ, Bruyn GW (eds). Handbook of clinical neurology, Vol 30. Amsterdam: North Holland Publ Co, 1977.

16. Jeret JS, Serur D, Wisniewski KE, Lubin R. Clinicopathological findings associated with agenesis of the corpus callosum. Brain Dev 1987, 9: 255-264.

17. Kotlarek F, Rodewing R, Brull D. Computed tomographic findings in congenital hemiparesis in childhood and their relation to etiology and prognosis. Neuropediatrics 1981, 2: 101-109.

18. Landy H, Ramsay E, Ajmone-Marsan C, Levin B, Brown J, Pasarin G, Quencer R. Temporal lobectomy for seizures associated with unilateral schizencephaly. Surg Neurol 1992, 37: 477-481.

19. Loeser J, Alvord EC. Agenesis of the corpus callosum. Brain 1968, 91: 553-570.

20. Martinez-Bermejo A, Lopez V, Arcas J, Perez-Higueras A, Morales C, Pacual-Castroviejo I. Early infantile epileptic encephalopathy: a case associated with hemimegalencephaly. Brain Dev 1992, 12: 425-428.

21. Miller GM, Stears JC, Guggenheim MA, Wilkening GN. Schizencephaly: a clinical and CT study. Neurology 1984, 34: 997-1001.

22. Murphy JP, Garvin JS. The EEG in porencephaly. Arch Neurol Psychiatry 1947, 58: 436-446.

23. Page LK, Broen SB, Gargano SP, Shortz RW. Schizencephaly: a clinical study and review. Child's Brain 1975, 1: 348-358.

24. Paladin F, Chiron C, Dulac D, Plouin P, Ponsot G. Electroencephalographic aspects of hemimegalencephaly. Dev Med Child Neurol 1989, 31: 377-383.

25. Pampliglione G, Lawrence KM. Electroencephalographic and clinico-pathological observations in hydrocephalic children Arch Dis Child 1962: 37: 491-499.

26. Probst PP. The prosencephalies. Berlin: Springer-Verlag, 1979. 
27. Robain O, Floquet $\mathrm{CH}$, Heldt N, Rozenberg F. Hemimegalencephaly: a clinicopathological study of four cases. Neuropathol Appl Neurobiol 1988, 14: 125-135.

28. Shoda T, Murase M, Saheki S, Takeuchi N. Holoprosencephaly: a case of holoprosencephaly with a flat EEG. Jpn J Clin Pathol 1990, 38: 1205.

29. Toglia JU, Lapayowker MS. Agenesis of the corpus callosum. Confinia Neurol 1966, 27: 342-366.

30. Warkany J, Lemire R, Cohen MM. Mental retardation and congenital malformations of the central nervous system. London: Year Book Med Publ 1981.

31. Yakovlev PL, Wadsworth RC. Schizencephalies: a study of the congenital clefts in the cerebral mantle. I. Clefts with fused lips. J Neuropathol Exp Neurol 1946, 5: 116-130.

32. Yakovlev PL, Wadsworth RC. Schizencephalies: a study of the congenital clefts in the cerebral mantle. II. Clefts with hydrocephalus and lips separated. J Neuropathol Exp Neurol 1946, 5: 169-205. 